\title{
Utilizing the Logistic Regression Model in Analyzing the Categorical Data of Economic Effects
}

\author{
${ }^{1 *}$ Mahdi Wahhab Neamah, ${ }^{2}$ Enas abid alhafidh Mohamed albasri, ${ }^{3}$ Zainb Hassan Rathy \\ 1* Department of Statistics, Faculty of Administration and Economics, Kerbala University, Iraq \\ mehdi.wahab@uokerbala.edo.iq \\ ${ }^{2}$ Department of Statistics, Faculty of Administration and Economics, Kerbala University, Iraq \\ enas.albasri@uokerbala.edu.iq \\ ${ }^{3}$ College of computer science and information technology - University of Al-Qadisiyah - Iraq \\ Zainb.hassan@qu.edu.iq
}

Article History: Received:11 January 2021; Accepted: 27 February 2021; Published online: 5 April 2021

\begin{abstract}
The categorical data has a significant role in representing statistical binary variables, and they are analyzed by means of grouping the response variable into ordered categories. Thereby, the dependent variable becomes of type binary qualitative variable. The data related to the financial position of world countries is classified within the categorical data. This work is to study the economic effects of an individual's different factors on determining the richness or poorness levels of a selected population of countries. Moreover, a logistic regression model is to be created to estimate these levels. As a sample of research, the categorical data relevant to the financial status of 20 Arabic countries were drawn from the website of the World Bank, WB. In addition, for comparison purpose, another similar set of categorical data was generated by MATLAB too. The paper has been based on two hypotheses, first is the well-known regression models, like the ordinary least squares or maximum likelihood, are not accurate in case of binary qualitative variables. Second, is utilizing the logistic regression model as an alternative model to achieve the paper goal. The paper results, for both WB data and MATLAB data, have successfully proved the ability of the logistic regression model in manipulating the categorical data and predicting the coefficients of the corresponding regression models.
\end{abstract}

\section{Introduction}

Qualitative variables are of binary values ( 0 or 1 ) (Yes or No) are almost based on the variable nature (e.g. colour of the eye, black or blue, / gender, male or female, etc.). Regression models of these variables cannot be accurately estimated by applying the conventional regression methods, such as the Ordinary Least Squares method (OLS). This is because the conventional models encounter several problems when used in estimating the coefficients of regression models whose dependent variables are qualitative. These problems can be summarized by; Multicollinearity, Autocorrelation and the non-homogeneous variance. [1-2][3B][4-6].

Alternatively, the logistic regression model, of binary response, is regarded as the most proper model to overcome such obstacles. For logistic regression, the predicted dependent variable is expressed by a function of the probability that a certain event will be in one of the binary categories which commonly specified by (true or false) (zero or one). Practically, it is not possible to create a regression model for binary data. Therefore, Mathematical solution is presented by the logistic regression model, LGM, by utilizing a logarithm function called "logit". This function is regarded as a transfer function to transfer the probability of binary events into non-binary regression values [16-20].

$Y=\operatorname{logit}=\ln \left(\frac{p}{1-p}\right)$

Where $p$ is the probability that the logistic regression value is at logic "one" which means a certain event is true. In contrast, $1-p$ is the probability of the logistic regression value is "zero"; i.e., the event is false. Accordingly, the range of dependent variable value " $Y$ " will vary from negative infinity, when $\mathrm{p}=0$, to positive infinity, when $\mathrm{p}=1$. Then, it becomes predictable by the conventional regression models like the OLS or the maximum likelihood, ML [2] [8-12]. So:

$$
Y=\beta_{o}+\beta_{1} X_{1}+\beta_{2} X_{2} \ldots+\beta_{n} X_{n}
$$




\section{Description of the data}

The economic statistical data employed in this work, to achieve the paper issue, were drawn from the website of the World Bank (WB), for the year 2019. The WB publishes, on its website, a per capita Gross Domestic Product (GPD) matrix. This GDP matrix breaks down the domestic economic outputs of the world countries (per person) relative to the country population [7]. Twenty of the Middle East Arab countries were selected for the paper study from the GPD matrix.

The data under study is of a binary response-dependent variable known as "Economic Status", which is equal to 1 if the country citizen has an annual income of more than 15 thousands USD. Otherwise, the dependent variable is of zero value. There are five predictors $\mathrm{X} 1, \mathrm{X} 2, \mathrm{X} 3, \mathrm{X} 4$ and $\mathrm{X} 5$ to specify the person; annual income, life rate, school life, unemployment condition and the continental location( 1 for Asia and 0 for Africa) respectively. The predictors X2 through X5 explicitly affect the value of X1 predictor, which was determined, in this work, as a base to define the dependent variable status.

\section{Description of the proposed model}

Figure 1 is a descriptive block diagram to illustrate the various stages of the proposed logistic regression model. The predictors $\mathrm{X} 1$ through $\mathrm{X} 4$, which have continuous values, are fed to the logistic decision block. In addition, the predictor X5 (which labelled by cont. because it is represented by " 0 " or " 1 " binary values) is also fed to this block. The output of the logistic decision block is the dependent variable in its binary form "0" or " 1 ". This output form represents the input of the "log function" block which has to widen the range of the independent variable "Y" into (infinity to +infinity). By this range transformation, values of " $Y$ " become ready to be manipulated by the likelihood estimation block. The output of this block is the required logistic regression model.

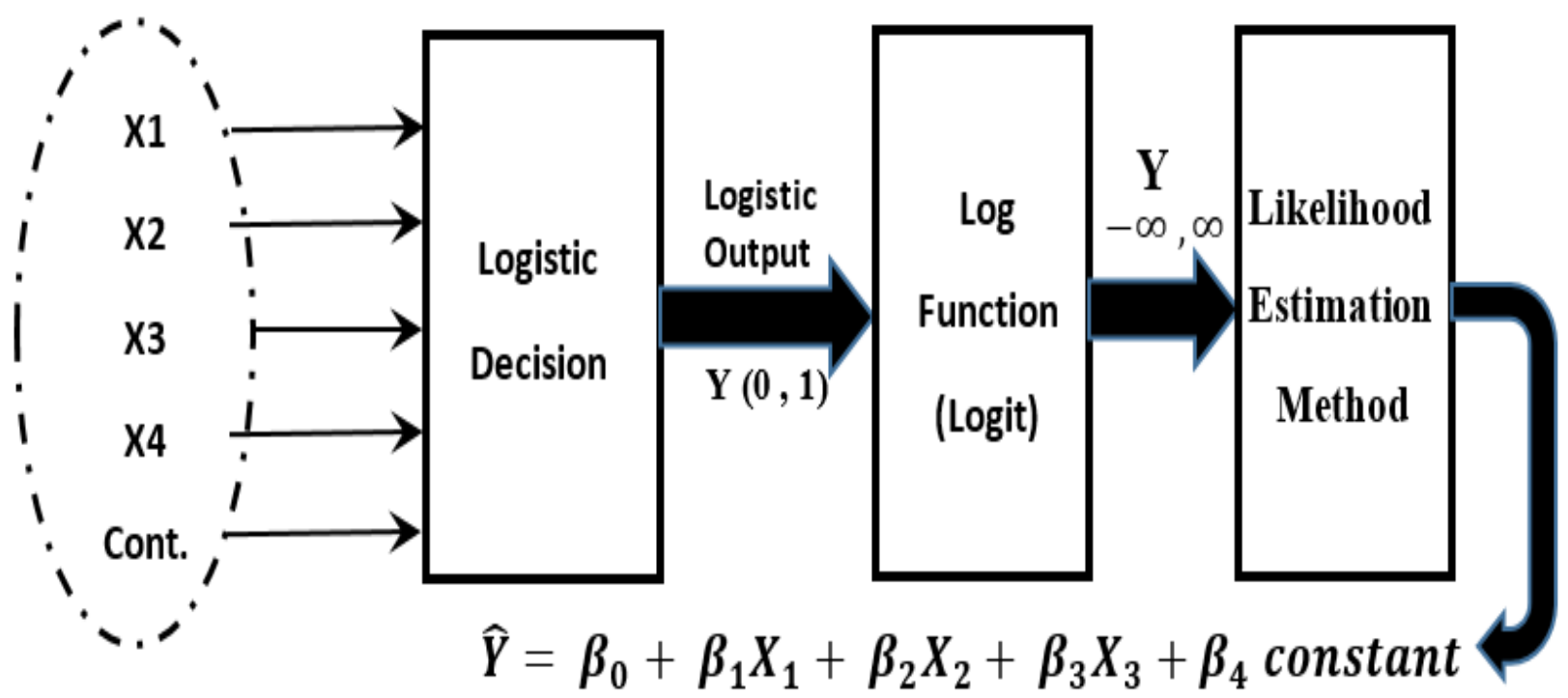

Fig. 1 The proposed logistic regression model

\section{Results and Discussion}

The data under this study is shown in appendices.1 and 2. This data was fed and processed by the statistical software SPSS. The output results of this software for the data of appendix 1 are shown and discussed by the tables shown in figures 2 through 6 given below.

Figure 2 shows the sample size utilized in this work. It tells that all the twenty input data of the twenty countries, concerned in this study, were processed and there is no any missing in the input data. 


\section{Case Processing Summary}

\begin{tabular}{llrr} 
Unweighted Cases $^{\text {a }}$ & N & Percent \\
\hline Selected Cases & Included in Analysis & 20 & 100.0 \\
\cline { 2 - 4 } & Missing Cases & 0 & .0 \\
\cline { 2 - 4 } & Total & 20 & 100.0 \\
\hline \multirow{2}{*}{ Unselected Cases } & 0 & .0 \\
\hline Total & 20 & 100.0 \\
\hline
\end{tabular}

a. If weight is in effect, see classification table for the total number of cases.

Fig. 2, Statistic for the undertaken sample data

Figure 3a illustrates the two states binary coding of the dependent variable, Y, (the work outcome) and its corresponding classification into explanatory categorizes poor and rich. While figure $3 \mathrm{~b}$ points out the numbers for "poor" and "rich" cases (14 and 6 respectively) and the overall poorness percentage (70\%)
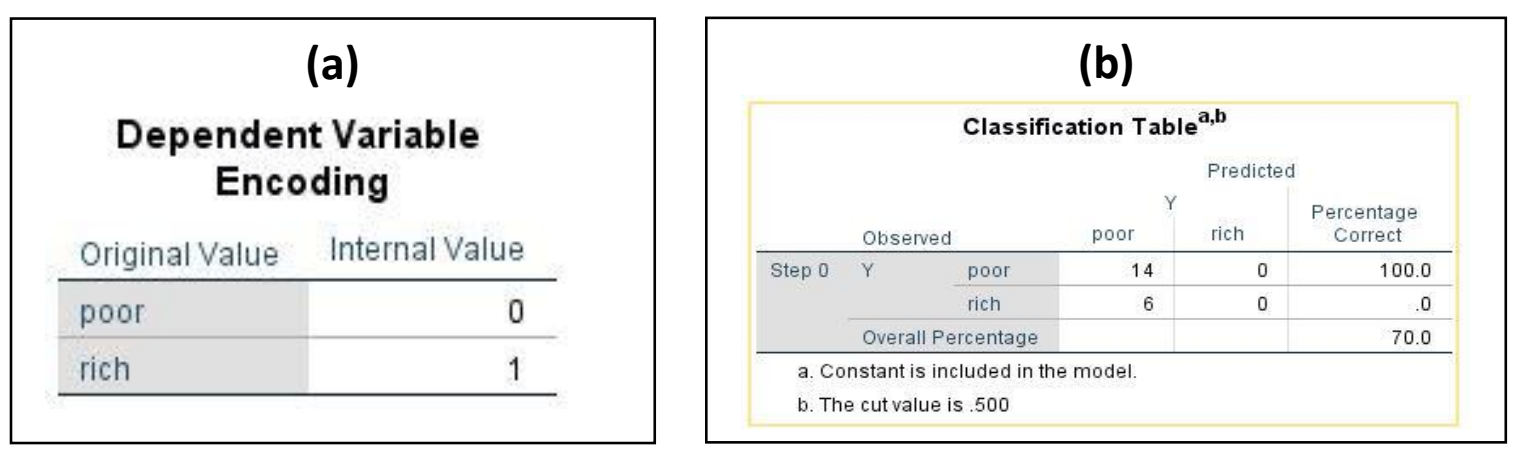

Fig. 3, Coding and classification of the dependent variable

Table for variables in the equation is given in figure 4 . By the last column in this table, it can be noticed that the value 0.429 represents the right-hand side of the logit logistic function. This value comes from the following:

By figure 3, probability of true $=\mathrm{p}=6 / 20=0.3$

So, logit $\left(\frac{p}{1-p}\right)=\ln \left(\frac{0.3}{0.7}\right)=0.429$

\begin{tabular}{|ll|l|l|l|l|l|r|}
\hline \multicolumn{8}{|c|}{ Variables in the Equation } \\
& B & S.E. & Wald & df & Sig. & Exp (B) \\
\hline Step 0 & Constant & -.847 & .488 & 3.015 & 1 & .082 & .429 \\
\hline
\end{tabular}

Fig. 4, Coding and classification of the dependent variable 
Figure 5 shows the table of the iteration history of estimations of the predictor coefficients. The proposed model was constructed by a procedure based on an iterative maximum likelihood, ML. The initial values of the regression coefficients, $\beta \mathrm{s}$, were arbitrarily chosen. In each iteration, the SPSS predicted new, more accurate values for regression coefficients. Thereby, the likelihood of the observed data would be made greater under the new model coefficients. Iterations procedure continued till model converging was taken place, which means that the differences between the values of previous and current model coefficients can be are neglected. The iteration history table shows that the coefficient estimations processes proceeded for 20 steps. The table also shows the deviance statistic (2LL). These statistics are obtained from the natural logarithm of likelihood multiplying by (-2). It represents a criterion of how the coefficient estimations are good and, correspondingly, how the logistic regression model exactly fit the data. The smaller value of this Statistic the better estimation of predictor coefficients [1] [13-15].

\begin{tabular}{|c|c|c|c|c|c|c|c|c|}
\hline \multicolumn{9}{|c|}{ Iteration History ${ }^{a, b, c, d}$} \\
\hline \multirow{2}{*}{\multicolumn{2}{|c|}{ Iteration }} & \multirow{2}{*}{$\begin{array}{l}-2 \log \\
\text { likelihood }\end{array}$} & \multicolumn{6}{|c|}{ Coefficients } \\
\hline & & & Constant & $x_{1}$ & $\times 2$ & $\times 3$ & $\times 4$ & $\times 5$ \\
\hline \multirow[t]{20}{*}{ Step 1} & 1 & 8.945 & 4.684 & .000 & -.116 & .176 & -.025 & -.776 \\
\hline & 2 & 4.205 & 9.468 & .000 & -.211 & .266 & -.067 & -1.136 \\
\hline & 3 & 1.766 & 16.395 & .000 & -.309 & .236 & -.163 & -1.285 \\
\hline & 4 & .684 & 24.241 & .000 & -.412 & .156 & -.282 & -1.300 \\
\hline & 5 & .265 & 32.261 & .001 & -.520 & .086 & -.402 & -1.264 \\
\hline & 6 & .102 & 40.673 & .001 & -.637 & .027 & -.529 & -1.180 \\
\hline & 7 & .039 & 49.476 & .001 & -.760 & -.026 & -.662 & -1.048 \\
\hline & 8 & .015 & 58.578 & .001 & -.889 & -.075 & -.800 & -.879 \\
\hline & 9 & .005 & 67.883 & .001 & -1.022 & -.120 & -.942 & -.684 \\
\hline & 10 & .002 & 77.318 & .001 & -1.158 & -.160 & -1.084 & -.476 \\
\hline & 11 & .001 & 86.837 & .001 & -1.296 & -.198 & -1.227 & -.260 \\
\hline & 12 & .000 & 96.411 & .001 & -1.435 & -.233 & -1.370 & -.041 \\
\hline & 13 & .000 & 106.024 & .002 & -1.575 & -.267 & -1.513 & .179 \\
\hline & 14 & .000 & 115.663 & .002 & -1.716 & -.299 & -1.656 & .399 \\
\hline & 15 & .000 & 125.324 & .002 & -1.858 & -.330 & -1.798 & .617 \\
\hline & 16 & .000 & 135.002 & .002 & -2.000 & -.360 & -1.941 & .835 \\
\hline & 17 & .000 & 144.694 & .002 & -2.142 & -.389 & -2.084 & 1.051 \\
\hline & 18 & .000 & 154.397 & .002 & -2.285 & -.418 & -2.226 & 1.267 \\
\hline & 19 & .000 & 164.110 & .002 & -2.428 & -.446 & -2.368 & 1.481 \\
\hline & 20 & .000 & 173.831 & .002 & -2.571 & -.474 & -2.511 & 1.695 \\
\hline \multicolumn{9}{|c|}{ a. Method: Enter } \\
\hline \multicolumn{9}{|c|}{ b. Constant is included in the model. } \\
\hline \multicolumn{9}{|c|}{ c. Initial -2 Log Likelihood: 24.435} \\
\hline \multicolumn{9}{|c|}{ d. Estimation terminated at iteration number 20 because maximum iterations has been reached. } \\
\hline
\end{tabular}

Fig. 5, History of predictor coefficient estimations 
The most important table is the one given in figure 6. It demonstrates the results of the estimation of coefficients of the logistic regression model. According to these results, the estimated output (Y) of the undertaken logistic regression model is given by:

$Y=173.831+0.002 X 1-2.571 X 2-0.474 X 3-2.511 X 4+1.695 X 5$

Fig. 6, Variables of the logistic regression equation by WB data

It is clear that the estimated logistic model is well consistent with the economic standards in financial

\begin{tabular}{|c|c|c|c|c|c|c|c|}
\hline \multicolumn{8}{|c|}{ Variables in the Equation } \\
\hline & & B & S.E. & Wald & df & Sig. & $\operatorname{Exp}(B)$ \\
\hline \multirow[t]{6}{*}{ Step $1^{a}$} & $\mathrm{X} 1$ & .002 & 1.171 & .000 & 1 & .998 & 1.002 \\
\hline & $\mathrm{X} 2$ & -2.571 & 3369.584 & .000 & 1 & .999 & .076 \\
\hline & $\mathrm{X} 3$ & -.474 & 6871.214 & .000 & 1 & 1.000 & .622 \\
\hline & $X_{4}$ & -2.511 & 1747.026 & .000 & 1 & .999 & .081 \\
\hline & $x 5$ & 1.695 & 16080.307 & .000 & 1 & 1.000 & 5.448 \\
\hline & Constant & 173.831 & 164157.100 & .000 & 1 & .999 & $3.118 \mathrm{E}+75$ \\
\hline
\end{tabular}

developing of countries. Discussion of equation (3) can be summarised by the following points:

- The negative coefficients of the predictors $\mathrm{X} 2, \mathrm{X} 3$ and X4 mean that they have a negative effect on tending of output to be a state "1" "richness". Increasing the value of X2, X3 or X4 by one leads to reduce the logit of logistic regression by $2.571,0.474$ and 2.511 , respectively.

- In contrast, the X1 and X5 predictors have a positive effect on bringing the output up to "1" state. Increasing each of these predictors by one will improve the opportunity of the logit regression by 0.002 and 1.695 , respectively.

- According to the above two points, it is obviously clear that the person life period and its unemployment condition highly affect on reducing the output of the logistic model. In a reverse manner, the output rises with the person annual income and the Asian geographic position of the country.

- The exact output binary was categorizing of countries into poor " 0 ", and rich " 1 " without any per cent of error affect the value of Wald test making it equals to zero for all estimated coefficients.

Whereas the table given in figure 7 shows the results of the estimation of coefficients of the logistic regression model according to the data generated by MATLAB simulation.

\begin{tabular}{|c|c|c|c|c|c|c|c|c|c|}
\hline \multicolumn{10}{|c|}{ Variables in the Equation } \\
\hline & & \multirow[b]{2}{*}{ B } & \multirow[b]{2}{*}{ S.E. } & \multirow[b]{2}{*}{ Wald } & \multirow[b]{2}{*}{$\mathrm{df}$} & \multirow[b]{2}{*}{ Sig. } & \multirow[b]{2}{*}{$\operatorname{Exp}(B)$} & \multicolumn{2}{|c|}{$95 \%$ C.I.for $\operatorname{EXP}(B)$} \\
\hline & & & & & & & & Lower & Upper \\
\hline \multirow[t]{6}{*}{ Step $1^{\text {a }}$} & $\mathrm{X} 1$ & .003 & .692 & .000 & 1 & .997 & 1.003 & .258 & 3.894 \\
\hline & $\mathrm{X} 2$ & -.130 & 725.789 & .000 & 1 & 1.000 & .878 & .000 & . \\
\hline & $\mathrm{X} 3$ & 3.500 & 2766.404 & .000 & 1 & .999 & 33.106 & .000 & . \\
\hline & $\times 4$ & .110 & 302.180 & .000 & 1 & 1.000 & 1.117 & .000 & $1.838 \mathrm{E}+257$ \\
\hline & $\times 5$ & -1.015 & 9678.531 & .000 & 1 & 1.000 & .362 & .000 & . \\
\hline & Constant & -67.904 & 68570.788 & .000 & 1 & .999 & .000 & & \\
\hline
\end{tabular}


Fig. 7, Variables of the logistic regression equation by MATLAB data

So, the corresponding logistic equation for the MATLAB data is given by:

$Y=0.003-1302 X 1+3500 X 2+0.11 X 3-1.015 X 4-67.904 X 5$

\section{$\underline{\text { Verification }}$}

To verify the validity of the obtained logistic regression equation given in (3), the data of the first country, for instance, are substituted in the regression equation. By this substitution yields:

$$
Y=-38.24
$$

Taking the inverse of (logit) function yields:

$$
\frac{p}{1-p}=\text { value very close to zero }
$$

Result of equation (6) is correct if and only if the value of the probability of the country to be rich (p) is very close to zero. This means that the country whose date was substituted in the logistic regression equation (equation 3), is more likely to be a poor country. Thereby, the regression result well fit the data of the first country given in appendix 1. Similarly, if the data of the second country is substituted in the logistic regression equation, a value of (p) very close to one will be obtained. So, this country is more likely to be rich, which is consistent with this country data.

\section{Conclusions}

The paper projects a spot of light on the difficulties that may encounter the researchers when they try to apply the traditional regression tools on data of binary form. In addition, the results of this paper have confirmed the ability of the logistic regression model in dealing with the binary qualitative variables and accurately estimating the coefficients of the predicted regression model. It can be concluded that the logistic regression model is convenient in modelling the binary data because of its simplicity and its high explanatory meaning. Comparing the equations of regression models given by equations 3 and 4 has shown that the value estimated coefficients and their effects differ according to the data to be manipulated.

\section{References}

1- A. A. Tôrres FernandesI and et al., Read this paper if you want to learn logistic regression,

2- A. K. Abaas, Using the Logistic Regression Model to Estimate the Functions of Qualitative Economic Dependent Variables, Journal of Kirkuk University for Administrative and Economic Sciences, 2 (2012), 234-253.

3- A. AGRESTI, An Introduction to Data Categorical Analysis, Wiley Series in Probability and Statistics, United States, 2019.

4- D. L. HOFFMAN and G. FRANKE, Correspondence Analysis: Graphical Representation of $\mathrm{n}$ Categorical Data in Marketing Research, Journal of Marketing Research, Vol. XXIII (August 1986), 213-27

5- E. Brentari, S. Golia and M. Manisera, Models for Categorical Data: A Comparison between the Rasch Model and Nonlinear Principal Component Analysis, Statistica \& Applicazioni, V (2007) 53-77

6- https://www.investopedia.com/terms/p/per-capitagdp.asp\#: :text=Per\%20capita\%20gross\%20domestic\%20product,a\%20country\%20by $\% 20$ its $\% 20$ populati on., available on 18 Dec. 2020

7- https://unstats.un.org/unsd/demographic/products/socind/default.htm, available on 18 Dec. 2020. 
8- J. Malar and T. Bhuvaneswari, Data Quality Measurement on Categorical Data Using Genetic Algorithm, International Journal of Data Mining \& Knowledge Management Process (IJDKP), 2 (2012) 33-42.

9- Hole, Y., \& Snehal, P. \& Bhaskar, M. (2019). Porter's five forces model: gives you a competitive advantage. Journal of Advanced Research in Dynamical and Control System, 11 (4), 1436-1448.

10- L. D. Ambraa, O. Köksoyb and B. Simonettic, Cumulative correspondence analysis of ordered categorical data from industrial experiments, Journal of Applied Statistics 36 (2009) 1315-1328.

11- M. B. Pietrzak and et al., The Application Of Local Indicators For Categorical Data (LICD) In The Spatial Analysis Of Economic Development, Comparative Economic Research, 17 (2014) 203-220.

12- M. E. Aguilar and et al., Logistic Regression Model for the Academic Performance of First-Year Medical Students in the Biomedical Area, Creative Education, 7 (2016) 2202-2211

13- M. Mustapha, F. W. Usman and S. Yusuf, A Logistic Regression Model on Academic Performance of Students in Mathematics, Continental J. Applied Sciences 11 (2016) $1-15$.

14- O. A. Maydeu and J. Harry, Assessing Approximate Fit in Categorical Data Analysis, Multivariate Behavioral Research, 49 (2014) 305-328.

15- Q. H. Vuong, N. K. Napier and T. D. Tran, A categorical data analysis on relationships between culture, creativity and business stage: the case of Vietnam, Int. J. Transitions and Innovation Systems, 3, (2013) 4-24.

16- R. Serban, A. Kupraszewicz and G. Hu, "Predicting the characteristics of people living in the South USA using logistic regression and decision tree," 9th IEEE International Conference on Industrial Informatics, Caparica, Lisbon, 2011, pp. 688-693.

17- S, Byron, K. Rachel and R. Chris, Practical Applications of Correspondence Analysis to Categorical Data in Market Research, 5 (1996) 56-70

18- S. A. Mingoti and R. A. Matos, Clustering Algorithms for Categorical Data: A Monte Carlo Study, International Journal of Statistics and Applications 2 (2012) 24-32.

19- S. Alija, H. Snopce and A. Aliu, Logistic Regression for Determining Factors Influencing Students Perception of Course Experience, The Eurasia Proceedings of Educational \& Social Sciences (EPESS), 5 (2016) 99-106.

20- S. Mabula, Modeling Student Performance in Mathematics Using Binary Logistic Regression at Selected Secondary Schools, Journal of Education and Practice, 6 (2015) 96-103.'

21- Yogesh Hole et al 2019 J. Phys.: Conf. Ser. 1362012121

22- X. Zou, Y. Hu, Z. Tian and K. Shen, "Logistic Regression Model Optimization and Case Analysis," IEEE 7th International Conference on Computer Science and Network Technology, Dalian, China, 2019, pp. 135-139.

Appendix1: Data from the WB [7]

\begin{tabular}{|c|c|c|c|c|c|c|c|}
\hline No. & Country & $\begin{array}{c}\text { Annual } \\
\text { Person } \\
\text { Income } \\
(\$)\end{array}$ & $\begin{array}{c}\text { Life } \\
\text { expectancy } \\
\text { (Years) }\end{array}$ & $\begin{array}{c}\text { School life } \\
\text { expectancy } \\
\text { (Years). }\end{array}$ & $\begin{array}{l}\text { Unemploy } \\
\text { ment rate }\end{array}$ & $\begin{array}{c}\text { Continental } \\
\text { location ( } \\
\text { Asia=1, } \\
\text { Africa=0) }\end{array}$ & $\begin{array}{c}\text { Economic } \\
\text { status } \\
(\text { poor }=0, \\
\text { rich }=1)\end{array}$ \\
\hline & & $\mathrm{X} 1$ & $\mathrm{X2}$ & $\mathrm{X3}$ & $\mathrm{X4}$ & Cont. & $\mathbf{Y}$ \\
\hline 1 & Algeria & $3,974.0$ & 72 & 13 & 8.1 & 1 & 0 \\
\hline 2 & Bahrain & $23,504.0$ & 75 & 13 & 5.6 & $\mathbf{0}$ & 1 \\
\hline 3 & Djibouti & $3,414.9$ & 57 & 6 & 54.6 & 1 & 0 \\
\hline 4 & Egypt & $3,019.2$ & 72 & 12 & 4.9 & 1 & 0 \\
\hline 5 & Iraq & $5,955.1$ & 68 & 12 & 16.2 & $\mathbf{0}$ & 0 \\
\hline 6 & Jordan & $4,405.5$ & 72 & 12 & 11 & 0 & 0 \\
\hline
\end{tabular}


${ }^{1 *}$ Mahdi Wahhab Neamah, ${ }^{2}$ Enas abid alhafidh Mohamed albasri, ${ }^{3}$ Zainb Hassan Rathy

\begin{tabular}{|c|c|c|c|c|c|c|c|}
\hline 7 & Kuwait & 32000.5 & 74 & 13 & 2 & 0 & 1 \\
\hline 8 & Lebanon & $7,583.7$ & 71 & 13 & 8.6 & 0 & 0 \\
\hline 9 & Libya & $7,685.9$ & 73 & 16 & 7.6 & 1 & 0 \\
\hline 10 & Mauritania & $1,679.4$ & 57 & 8 & 23.9 & 1 & 0 \\
\hline 11 & Morocco & $3,204.1$ & 70 & 11 & 8.4 & 1 & 0 \\
\hline 12 & Oman & $15,343.1$ & 71 & 13 & 1.9 & 0 & 1 \\
\hline 13 & Qatar & $62,088.2$ & 79 & 12 & 0.2 & 0 & 1 \\
\hline 14 & Saudi Arabia & $23,139.8$ & 73 & 14 & 3.5 & 0 & 1 \\
\hline 15 & Somalia & $1,26.9$ & 50 & 3 & 26.1 & 1 & 0 \\
\hline 16 & Sudan & $4,41.5$ & 60 & 10 & 18.7 & 1 & 0 \\
\hline 17 & Syria & $2,032.6$ & 74 & 12 & 5.7 & 0 & 0 \\
\hline 18 & Tunisia & $3,317.5$ & 73 & 14 & 11.9 & 1 & 0 \\
\hline 19 & United & $43,103.3$ & 76 & 11 & 2 & 0 & 1 \\
\hline 20 & Yemirates & 774.3 & 65 & 11 & 12.4 & 0 & $\ddots 0$ \\
\hline
\end{tabular}

Appendix2: Data by the MATLAB

\begin{tabular}{|c|c|c|c|c|c|c|c|}
\hline \multirow{2}{*}{ No. } & Country & $\begin{array}{c}\text { Annual } \\
\text { Person } \\
\text { Income (\$) }\end{array}$ & $\begin{array}{c}\text { Life } \\
\text { expectancy } \\
\text { (Years) }\end{array}$ & $\begin{array}{c}\text { School life } \\
\text { expectancy } \\
\text { (Years). }\end{array}$ & $\begin{array}{c}\text { Unemploy } \\
\text { ment rate }\end{array}$ & $\begin{array}{c}\text { Continental } \\
\text { location ( } \\
\text { Asia=0 , } \\
\text { Africa=1) }\end{array}$ & $\begin{array}{c}\text { Economic } \\
\text { status } \\
\text { poor=0 } \\
\text { rich=1) }\end{array}$ \\
\cline { 2 - 8 } & X1 & X2 & X3 & X4 & Cont. & Y \\
\hline 2 & C2 & 22,418 & 56 & 12 & 28.342 & 1 & 1 \\
\hline 3 & C3 & 18,290 & 73 & 12 & 32.383 & 1 & 1 \\
\hline 4 & C4 & 38,175 & 60 & 8 & 8.596 & 1 & 1 \\
\hline 5 & C5 & 31,394 & 52 & 11 & 11.072 & 1 & 1 \\
\hline 6 & C6 & 38,599 & 80 & 8 & 22.442 & 1 & 1 \\
\hline 7 & C7 & 46,642 & 60 & 12 & 41.204 & 1 & 1 \\
\hline 8 & C8 & 48,637 & 68 & 11 & 45.425 & 1 & 1 \\
\hline 9 & C9 & 9,601 & 78 & 8 & 43.469 & 0 & 0 \\
\hline
\end{tabular}




\begin{tabular}{|l|l|l|l|l|l|l|l|}
\hline 10 & $\mathrm{C} 10$ & 6,943 & 64 & 6 & 17.587 & 1 & 0 \\
\hline 11 & $\mathrm{C} 11$ & 34,813 & 79 & 12 & 29.420 & 1 & 1 \\
\hline 12 & $\mathrm{C} 12$ & 4,691 & 66 & 13 & 5.038 & 1 & 0 \\
\hline 13 & $\mathrm{C} 13$ & 26,270 & 77 & 7 & 6.233 & 1 & 1 \\
\hline 14 & $\mathrm{C} 14$ & 26,517 & 78 & 11 & 7.582 & 0 & 1 \\
\hline 15 & $\mathrm{C} 15$ & 43,056 & 68 & 8 & 37.358 & 1 & 1 \\
\hline 16 & $\mathrm{C} 16$ & 24,242 & 51 & 12 & 27.285 & 0 & 1 \\
\hline 17 & $\mathrm{C} 17$ & 19,672 & 63 & 11 & 10.515 & 0 & 1 \\
\hline 18 & $\mathrm{C} 18$ & 33,571 & 67 & 6 & 27.276 & 1 & 1 \\
\hline 19 & $\mathrm{C} 19$ & 37,062 & 61 & 12 & 8.204 & 1 & 1 \\
\hline 20 & $\mathrm{C} 20$ & 26,002 & 58 & 13 & 3.118 & 1 & 1 \\
\hline
\end{tabular}

